PontIFÍCIA UNIVERSIDADE CATÓLICA do RIO DE JANEIRO

Viabilidade Econômico-financeira de Filmes Brasileiros

\title{
Phillip Cattley
}

Trabalho de Conclusão de Curso

Centro de ciências socials - CCS

DEPARTAMENTO DE ADMINISTRAÇÃO

Graduação em Administração de Empresas 


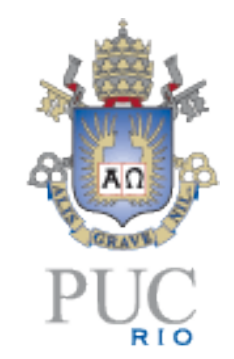

Phillip Cattley

\title{
Viabilidade Econômico-financeira de Filmes Brasileiros
}

\author{
Trabalho de Conclusão de Curso
}

Trabalho de Conclusão de Curso, apresentado ao programa de graduação em Administração da PUC-Rio como requisito parcial para a obtenção do titulo de graduação em Administração.

Orientadora : Liana Ribeiro dos Santos

Rio de Janeiro

Novembro de 2017 


\section{Agradecimentos}

A Deus, que me acompanha sempre, que me deu vida, que me ama.

Para meu pai Kenneth, que me apoia em tudo que eu faço, e sempre acreditou no meu potencial.

Para meu irmão Kevin, meu primeiro amigo, de quem tenho grande orgulho.

Para minha mãe Mayra, e minha irmã Stephanie, por quem tenho grande carinho e amor.

Para meus avós Sylvio e Lizeth, por sempre estarem presentes, e por serem segundos pais, para mim e meu irmão.

Para Ana, minha companheira, que me apoia nos meus sonhos, me fortalece, e enriquece a minha vida de maneira que não consigo medir.

Para meus amigos: Bernardo, Paulo, Anderson, Igor, Renato, James, Olívia, Luciana, Kleber, Piero, Nicole, Israel, Pedro, Bianca, André, pelas grandes contribuições que suas amizades, apoio e bom humor tem na minha vida.

Para minha Orientadora e Professora, Liana Ribeiro, pelos seus ensinamentos, paciência, e apoio nesta fase importante da minha vida.

Para todos os meus professores da PUC-Rio, que contribuíram para o meu desenvolvimento pessoal e profissional, com destaque para: Sérgio Nobrega de Oliveira, Alexandre de Souza Chaves, Leonardo Lima Gomes, Flávia da Costa Limmer, Rui Ronald Marinho, Ana Cláudia Oliveira da Silva Pinheiro, Ulisses Felipe Camardella, Liana Ribeiro dos Santos, Anna Maria Soterro, Marcela Figueiredo de Oliveira, Isao Nishioka. Pela paciência, atenção, generosidade, paixão pelos ensinamentos, instrução e apoio. Sou extremamente grato.

Para a PUC-Rio, onde pude me desenvolver pessoalmente e profissionalmente, onde venci obstáculos, cresci, e me tornei mais capaz, e mais feliz. 


\section{Resumo}

Cattley, Phillip. Viabilidade Econômico-financeira de Filmes Brasileiros. Rio de Janeiro, 2017. Número de páginas p. 45 Trabalho de Conclusão de Curso - Departamento de Administração. Pontifícia Universidade Católica do Rio de Janeiro.

Filmes foram sempre considerados, não somente um meio de entretenimento popular, mas também, em alguns casos, ótimos meios de investimento. Não obstante o retorno invejável de algumas produções, alguns investidores desconsideram filmes - quase que automaticamente - quando estão a procura de um bom e rentável investimento. Seriam filmes investimentos arriscados, inacessíveis ou, por quaisquer razões, desinteressantes? Teriam os investidores as informações necessárias para alocar seus recursos em filmes com confiança? Vale a pena investir nesta indústria? Esta tese tem o objetivo de responder a estas perguntas, bem como desmistificar filmes no Brasil como forma de investimento.

Palavras-chave: Filmes, Investimento, Rentabilidade, Ancine, Incentivos

\section{Abstract}

Cattley, Phillip. The Feasibility of Brazilian Movies. Rio de Janeiro, 2017. Number of pages p. 45 Trabalho de Conclusão de Curso - Departamento de Administração. Pontifícia Universidade Católica do Rio de Janeiro.

Movies have always been regarded as not just a popular way of entertainment, but also, in some cases, an excellent means for investment. Yet, notwithstanding enviable rates of return boasted by some productions, a number of investors seem to disregard film almost automatically when considering where to put their money. Are film productions risky, inaccesibe or unnatractive? Do investors lack the information with which to invest their money confidently? Does the industry merit a closer look in the first place, or not? This thesis aims to answer these questions as well as demistify movies as forms of investment in Brazil, bringing investors closer to this medium.

\section{Key-words}

Feasibility, Films, Movies, Investment, Ancine, Incentives 


\section{Sumário}

10 tema e o problema de estudo 1

1.1. Introdução ao tema e ao problema do estudo 1

1.2. Objetivo do estudo 2

1.3. Objetivos intermediários do estudo 3

1.4. Delimitação e foco do estudo 3

1.5. Justificativa e relevância do estudo 3

2 Revisão de literatura 5

2.1. Etapas da Produção de Filmes 5

2.2. Estrutura de Custos 6

2.3. Fontes de Financiamento $\quad 7$

2.4. Incentivos Fiscais 8

3 Métodos e procedimentos de coleta e de análise de dados do estudo 16

3.1. Estratégia de investigação OU Metódo de pesquisa utilizado 16

3.2. Fontes de informação selecionadas para coleta de dados no estudo16

3.3. Procedimentos e instrumentos de coleta de dados utilizados no $\begin{array}{ll}\text { estudo } & 17\end{array}$

3.4. Formas de tratamento e análise dos dados coletados para o estudo17

4 Apresentação e análise dos resultados 18

4.1. Os Filmes 18

4.2. Descrição dos resultados 19

4.2.1. Filme: Aquarius 19

4.2.2. Filme: 2 Coelhos 20

4.2.3. Filme: O Shaolin do Sertão 21

4.3. Análise dos resultados 22

4.3.1. Análise: Aquarius 22

4.3.2. Análise: 2 Coelhos 23

4.3.3. Análise: O Shaolin do Sertão 24 
5 Conclusões e recomendações para novos estudos

Anexo 1 - Fluxo descontado de bilheteria: Aquarius

Anexo 2 - Taxa Interna de Retorno: Aquarius

Anexo 3 - Fluxo descontado de bilheteria: 2 Coelhos

Anexo 4 - Taxa Interna de Retorno: 2 Coelhos

Anexo 5 - Fluxo descontado: O Shaolin do Sertão

Anexo 6 - Taxa Interna de Retorno: O Shaolin do Sertão

\section{Lista de figuras}

Figura 1: Fórmula de Cálculo do VPL.........................................................12

Figura 2: Fórmula de Cálculo do Modelo CAPM.........................................13

Figura 3: Fórmula de Cálculo da Taxa Interna de Retorno................................13

Figura 4: Fórmula de Cálculo do Payback Descontado.....................................14

Figura 5: Resultados do Filme: Aquarius.........................................................19

Figura 6: Resultados do Filme: 2 Coelhos...................................................20

Figura 7: Resultados do Filme: O Shaolin do Sertão.......................................21 


\section{Lista de Tabelas}

Tabela 1: Gastos em Filme, por Etapa......................................................

Tabela 2: Composição da CAPM...................................................................

Tabela 3: Simulação de VPL com CAPM modificada..........................................45 


\section{0 tema e o problema de estudo}

\subsection{Introdução ao tema e ao problema do estudo}

O Brasil atualmente se encontra em tempos de crise econômica. O PIB brasileiro sofreu retrações de 3,8\% em 2015 e 3,6\% em 2016 (World Bank Group, 2017). A produção industrial tem se mantido em níveis baixos desde Outubro 2014 (Portal da Indústria, 2017). Não obstante o crescimento esperado para certas indústrias, como a automobilística e têxtil (ABIT, 2017), (Dino, 2016), o nível de confiança de investidores, refletido por classificações de agências como Fitch (ALVARENGA, 2017), Moody's (ALVARENGA, 2017) e S\&Ps (ALVARENGA, 2017), continua baixo, e muitos setores continuam ameaçados por graves problemas políticos no país, os quais limitam o seu crescimento e recuperação.

Porém nem todas as indústrias foram afetadas pela crise política e econômica que o país vive. A indústria de filmes, no ano de 2016, bateu recorde de lançamento de filmes, tendo lançado 143 filmes no ano e vendido mais de 184 milhões de ingressos $(G 1,2016)$. Em 2016, 188 salas de cinema foram construídas, somandose as 3.168 salas já em funcionamento (G1, 2016), marcando um forte contraste com a produção industrial do país, que teve queda de $6,6 \%$ no ano passado (HESSEL, 2017). A título de exemplo, o filme brasileiro "Os Dez Mandamentos" foi responsável por obter o maior público do cinema nacional, com mais de 11,25 milhões de ingressos vendidos (MELO, 2016), enquanto que "Aquarius", outra produção brasileira, de escala significativamente menor, concorreu a Palma de Ouro, em Cannes, dentre outros prêmios. Ressalta-se, por oportuno, que Aquarius foi orçado em $\mathrm{R} \$ 3,4$ milhões e, até o final de 2016, já havia retornado aos seus investidores todo o capital investido (Wikipédia, 2017). 
Por que, então, protegidos da crise, com indústria em crescimento e com produções promissoras e rentáveis, filmes são descartados como forma de investimento? A verdade é que pouco é conhecido a respeito de filmes como forma de investimento. Um investidor experiente poderia especular com certa confiança quais seriam os principais custos de diversos empreendimentos, ou margens de lucro de diversos setores, porém, entenderia os principais custos envolvidos em uma produção de filme, ou saberia o retorno que pode esperar?

Antes de descartar qualquer investimento, é necessário coletar e analisar algumas informações sobre a proposta em questão. Propõem-se, então, verificar a viabilidade econômico-financeira de filmes brasileiros.

\subsection{Objetivo do estudo}

O objetivo deste estudo é verificar a viabilidade econômico-financeira de filmes brasileiros. Investidores precisam ter informação para comparar filmes com outros meios de investimento e, com base nestes dados, escolher como aplicar seu capital do melhor modo possível.

Fontes de receita e principais custos inerentes a produções cinematográficas serão abordados, visto que, com base nos custos, o investidor poderá comparar projetos, bem como identificar possíveis riscos na produção. Indicadores financeiros, como VPL, TIR e Payback, usados para determinar a atratividade de um investimentos frente a outros, também serão estudados, permitindo assim um melhor entendimento da rentabilidade de filmes em relação a investimentos em projetos de outros setores. Os principais riscos relacionados a investimentos em filmes também serão avaliados, visto que estes são particulares ao meio, e fundamentais para a tomada de decisão do investidor.

Com um entendimento sólido dos principais custos e riscos associados a uma produção cinematográfica, e conhecendo a rentabilidade de diversos projetos de filme, podendo assim compara-los a projetos potenciais, investidores podem começar sua procura por oportunidades em filmes com maior confiança, podendo 
assim usufruir do grande potencial que o mercado cinematográfico brasileiro tem para oferecer.

\subsection{Objetivos intermediários do estudo}

- Demonstrar as fontes de receita das quais um filme pode se beneficiar.

- Identificar os principais custos envolvidos na montagem de um filme, assim entendendo os que mais pesam em seu orçamento e contribuem para sua rentabilidade.

- Entender os principais riscos associados às etapas da produção de um filme, preparando o investidor para saber identificar o projeto mais lucrativo.

- Demonstrar a rentabilidade e atratividade de filmes de orçamento semelhante utilizando indicadores financeiros.

- Elucidar vantagens, como os benefícios fiscais concedidos a projetos cinematográficos, e mostrar como estes podem afetar a rentabilidade do investimento.

\subsection{Delimitação e foco do estudo}

Com o propósito de melhor entender filmes como objeto de investimento, 0 estudo compreenderá calcular médias de orçamentos e retornos de projetos. Para tornar o estudo mais viável e de maior relevância, as médias serão feitas a partir de uma amostra de filmes, todos nacionais e com orçamentos de valores semelhantes. Estes não ultrapassando o marco de U\$2,19 milhões, ou R\$7 milhões.

\subsection{Justificativa e relevância do estudo}

No que se diz respeito à relevância acadêmica, demonstrar a viabilidade de filmes brasileiros e divulgar os resultados poderá fomentar um maior debate sobre o tema em apresso dentro do ambiente acadêmico, trazendo mais informação de qualidade para alunos de administração e cinema, ou qualquer um que se interesse pelo tópico. 
Para o investidor, o estudo visa informar, para que este possa considerar filmes como forma de investimento e, consequentemente, aproveitar o crescimento de uma indústria em constante ascensão.

Criadores de filmes não podem sempre contar com apoio do governo para financiamento, contudo, se houver uma maior divulgação do seu índice de lucratividade, órgãos governamentais e entes privados terão mais interesse em investir neste ramo, o que poderá resultar em um aumento do número de produções nacionais. 


\section{Revisão de literatura}

\subsection{Etapas da Produção de Filmes}

"Produção cinematográfica é o processo de fazer um filme, de uma ideia inicial de história ou escrita do roteiro, filmagem, edição e finalmente distribuição para um público." (Sensagent, 2017)

Existem três etapas no processo de produção de um filme. São estas a préprodução, produção e pós-produção. A primeira etapa, pré-produção, de um filme inicia-se após a captação de recursos, e consiste em "uma organização sistemática de como serão conduzidas as filmagens" (SALLES, 2008). Nesta etapa, é necessário a elaboração de um cronograma para o projeto, bem como verificar a disponibilidade da equipe, atores, localizações, e quaisquer equipamentos, sejam estes técnicos ou artísticos que precisarão ser usados ao longo da filmagem (COLLUSSO, 2009). A aquisição dos direitos do argumento (roteiro) ou a elaboração do próprio também precisa ser feita, e todas as permissões para o processo de filmagem necessitam ser adquiridas. Em suma, é um processo de organização e de grande importância, que precisa ser definido e gerenciado para evitar o desperdício de tempo e capital ou problemas que podem ameaçar a continuidade do filme.

A segunda etapa é a de produção, onde o processo de filmagem começa, e onde todas as pessoas envolvidas no projeto; sejam estas atores, roteiristas, iluminadores, figurinistas, técnicos de som e imagem, filmadores, dentre inúmeras outras funções, prestam apoio ao diretor. Em outras palavras:

(...) cabe ao departamento de produção ter certeza de que cada membro da equipe, cada cenário, cada objeto de cena, cada equipamento, cada peça de vestuário está em seu devido lugar, a ser utilizado pelo diretor quando necessário em cada fase da produção, no contexto de prazos e orçamentos. (RODRIGUES, 2007. p. 68)

A terceira e última etapa da produção de um filme é a pós-produção. Consiste em duas importantes etapas, são estas: a desmontagem do set de filmagem, e a 
finalização do filme (SALLES, 2008). Para desmontar um set, todos os equipamentos eletrônicos, incluindo câmeras e microfones, precisam ser desinstalados e removidos. Roupas e props filmagem devem ser retirados e, caso alugados, devolvidos. Construções de cenário devem ser desmontadas, e o que foi emprestado retornado ao seu devido lugar. Contratos firmados com atores e equipes também precisam ser encerrados, e as respectivas partes pagas (SALLES, 2008). No que diz respeito à finalização do filme, o arranjo da música precisa ser inserido e as várias cenas editadas, sendo os efeitos especiais inseridos.

Após a etapa de pós-produção, um filme segue para distribuição, sendo distribuído através de cinemas, festivais, serviços on demand: Net Now, AppleTv, Netflix, GooglePlay, DVDs e Blu-Ray, mediante contratos assinados com estas partes. Custos de divulgação, campanhas publicitárias e eventos estão presentes nesta etapa.

\subsection{Estrutura de Custos}

"A proporção relativa de cada tipo de custo em uma organização é conhecida como sua estrutura de custo" (GARRISON, 2013, p. 28).

Dentro de uma estrutura de custo, temos também os conceitos de custo fixo e custo variável. O Serviço Brasileiro de Apoio às Micro e Pequenas Empresas, SEBRAE, define um custo fixo como sendo "gastos que permanecem constantes, independente de aumentos ou diminuições na quantidade produzida e vendida (SEBRAE, 2016)", enquanto custos variáveis são "aqueles que variam diretamente com a quantidade produzida ou vendida, na mesma proporção. (SEBRAE, 2016)”

Uma estrutura de custo vai além de identificar os tipos e proporções de custos fixos e variáveis presentes em um projeto. Uma estrutura pode ser examinada de forma mais específica e.g. Custos por produto, custos por serviço, por cliente, por região geográfica, permitindo o escrutínio e análise de cada categoria e como esta impacta o negócio como um todo. Entendendo-se onde incidem as maiores despesas, pode ser o primeiro passo para reduzi-las. 
Os custos para a pré-produção, produção e pós produção de um filme podem ser consideráveis. Estes custos incluem escritores, atores, diretores, produtores, compositores e músicos, efeitos visuais, cenários, dublês, aluguel de câmeras e microfones, construção de set, aluguel de vestuário, entre outros. O gasto total para cada um desses fatores irá variar em função do tamanho e tipo de filme, bem como o lugar onde se incidem os custos. Um investidor potencial pode se utilizar de comparações entre tipos de custos de diferentes filmes, identificando discrepâncias entre custos ou oportunidades. Abaixo segue uma tabela, com os principais gastos de cada etapa da produção de um filme.

Tabela 1 - Gastos em filmes, por etapa.

\begin{tabular}{|l|l|l|}
\hline \multicolumn{1}{|c|}{ Pré-produção } & \multicolumn{1}{|c|}{ Produção } & \multicolumn{1}{c|}{ Pós-produção } \\
\hline Aquisição do roteiro & Diretor & Edição do filme \\
Pesquisa de localizações & Roteirista & Trilha sonora \\
Design de figurino & Atores & Títulos e créditos \\
Seleção da equipe técnica & Produtores & Dublagens \\
Seleção de elenco & Eameraman & Desmontagem do set \\
Design do set & Assistente de câmera & \\
Desenvolvimento do script & Técnicos som & \\
Pesquisa & Técnicos imagem & \\
Seguros & Figurinista & \\
Custos de viagem & Equipe construção de set & \\
Permissões de filmagem & Gerente de produção & \\
Pagamento de locações & Equipamento de câmera & \\
& Equipamento de som & \\
& Equipamento de luz & \\
& Alimentação & \\
\hline
\end{tabular}

Fonte: Phillip Cattley (2017)

\subsection{Fontes de Financiamento}

Empresas podem se utilizar de capital próprio ou capital de terceiros para o financiamento de projetos. As fontes de financiamento variam, e incluem: aumento do capital social, empréstimos bancários, desinvestimento de ativos, crédito de fornecedores, aluguel de ativos, recursos do sistema financeiro, leasing de ativos (Wikipédia, 2017), venture capital, programas de incentivo do governo, Crowdfunding, entre outras alternativas. 
Para um projeto de filme, os produtores podem pegar empréstimos bancários, venture capital ou usar capital próprio para fazer o filme. Alternativamente, podem usufruir de programas de incentivo do governo como o PRODECINE (FSA, 2017) da agencia nacional de cinema, bem como recorrer a incentivos fiscais, através das leis Audiovisual ou Rouanet, ou até mesmo utilizar métodos como Crowdfunding e "colocação de produto" para arrecadar recursos.

Por último, projetos cinematográficos bem sucedidos estão aptos a serem qualificados para o PAR ou PAQ. O Prêmio adicional de Renda, PAR, é um investimento direto realizado anualmente pela ANCINE (Ancine, 2017) "com o objetivo de estimular o maior diálogo da cinematografia nacional com o seu público. Contempla empresas produtoras, distribuidoras e exibidoras de filmes de longametragem (Ancine, 2017)". Através do incentivo, produtoras de filmes que obtiveram sucesso de bilheteria, recebem recursos adicionais para serem investidos exclusivamente no "desenvolvimento de projetos, complementação de recursos para filmagem ou finalização (Ancine, 2017)". Os valores concedidos no prêmio variam de acordo com o número de ingressos vendidos (Ancine, 2017).

O PAQ, ou Programa ANCINE de Incentivo à Qualidade do Cinema Brasileiro, é também um prêmio concedido a projetos cinematográficos de sucesso (Ancine, 2017). Diferente do PAR, cujo critério de premiação é o sucesso na bilheteria, o PAQ busca incentivar projetos que obtiveram reconhecimento por suas qualidades "técnicas e artísticas (Ancine, 2017)". A agência então premia projetos de acordo com o sucesso obtido, através de honrarias e prêmios, no circuito do festival de cinema (Ancine, 2017). Os valores concedidos em prêmios são fixados anualmente, sendo distribuídos de forma igualitária entre as empresas produtoras beneficiadas (Ancine, 2017), os recursos concedidos precisam necessariamente ser utilizados na produção de novos filmes (Ancine, 2017).

\subsection{Incentivos Fiscais}

"Incentivos fiscais fazem parte do conjunto de políticas econômicas que visam facilitar o aporte de capitais em uma determinada área através da cobrança de 
menos impostos ou de sua não-cobrança, visando o aquecimento econômico do respectivo território. (UFRGS, 2017)".

Incentivos fiscais, em relação a projetos como um todo, elevam a rentabilidade do investidor, sendo assim, figuram-se como importantes considerações a serem analisadas na escolha de um investimento. Sem o incentivo, é necessário o pagamento total dos impostos devidos, porém com o incentivo, o investimento é menor, proporcionando um maior retorno sobre o capital investido.

Existem dois tipos de incentivos concedidos para filmes, o fomento direto e o fomento indireto. Fomento direto consiste em "apoio financeiro à produção com recursos orçamentários próprios, mediante seleção e concursos públicos elaborados com base na Lei de Licitações (8.666/93) (FORNAZARI, 2006, p. 658)". Já o fomento indireto consiste na "autorização e fiscalização dos projetos com recursos de renúncia fiscal, de acordo com as leis: Rouanet e Lei do Audiovisual (FORNAZARI, 2006, p. 658)".

A Lei Rouanet, é um mecanismo de incentivo fiscal, que permite que contribuintes possam abater até $4 \%$ de seu imposto de renda, no caso de pessoa jurídica e 6\% para pessoa física (quero incentivar, 2017), para fins de doação ou para o patrocínio de projetos culturais.

No que se-diz respeito à Lei do Audiovisual, existe mais de uma possibilidade. Uma empresa produtora pode emitir certificados de investimento em até $80 \%$ dos fundos requeridos para financiar uma produção (ZAVERUCHA, 1996), desde que o valor emitido não ultrapasse da ordem de R\$3.000.000,00 (ZAVERUCHA, 1996). Os certificados de investimento por sua vez, permitem abater $100 \%$ dos recursos despendidos (limitado à 4\% IR) (ZAVERUCHA, 2006) na compra de papéis de investimento, que auferem ao comprador o direito de exibição de sua marca, podendo também oferecer direitos de comercialização de obras e de projetos de distribuição, exibição e infraestrutura (quero incentivar, 2006). 


\subsection{Fontes de Receita}

Receita: "Soma de todos os valores que uma pessoa física ou jurídica recebe dentro de determinado espaço de tempo, quanto a seus negócios, proventos ou rendas (Michaelis, 2017)".

O ditado inglês "never put all your eggs in one basket", ou, "nunca coloque todos os ovos dentro de uma só cesta", é um paralelo útil para demonstrar as desvantagens associadas a investir exclusivamente em um ativo. $\mathrm{O}$ mesmo conceito pode ser aplicado a receitas, visto que a falta de uma fonte alternativa de renda pode vir a comprometer o fluxo de caixa de um empreendimento caso a fonte apresente problemas. No que diz respeito à venda de uma empresa ou projeto, múltiplas fontes de receita podem ser atributos desejáveis a um comprador, visto que podem reduzir riscos, além de ampliar o potencial de receita/caixa da empresa.

Existem várias fontes de receita disponíveis para filmes, sendo algumas dependentes do sucesso de outras. É importante que o investidor de filmes entenda o potencial destas receitas quando contempla filmes como investimento. Podemos citar a venda de ingressos de cinema como primeira fonte de receita de filmes. Nesta fonte, existe um acordo entre os produtores de filme, e as empresas de exibição, ou cinemas. O valor acordado é baseado na venda de ingressos, e pode partir de uma quantia fixa, ou alternativamente, um percentual. No que se refere ao percentual, existe variação, visto que filmes em grande demanda tem poder de barganha diferente em relação a menores produções. Uma regra de mercado contempla que o exibidor retenha $50 \%$ do lucro de bilheteria de um filme, com os outros $50 \%$ sendo repassados ao distribuidor e produtor nas proporções de $30 \%$ e $70 \%$ respectivamente (STERNHEIM, 2013). Com termos acordados, o cinema ganha o direito de exibir um filme por um determinado período de tempo, sendo este, normalmente, de cinco anos (Anexo 7).

Podemos citar também a venda de DVDs e BluRay, bem como a venda dos direitos de exibição para streaming como fonte de receita importante para filmes. O mercado de DVDs no Brasil tem diminuído com o aumento de serviços por demanda, podemos calcular uma retração de $22 \%$ do número de obras lançadas em DVD do 
ano de 2015 para 2016, e um crescimento de 68\% do número de serviços de vídeo por demanda entre os anos 2012 e 2016 (OCA, 2017). Não obstante a redução no número de DVDs vendidos, e a clara preferência do brasileiro pelo mercado de streaming- Netflix cresceu seu número de assinantes em mais de $87 \%$ de Outubro 2015 para Setembro 2016 (meio\&mensagem, 2016) - DVDs de filmes brasileiros tem apresentado um crescimento em lançamentos de 74\% (OCA, 2017), mostrando uma maior atuação de produções brasileiras no mercado audiovisual, e trazendo oportunidades para potenciais investidores.

Os direitos autorais de um filme, incluindo sua trama, personagens e todo seu universo fictício, podem ser alugados ou vendidos por acordos de merchandising. Assim, empresas fabricantes de produtos como camisetas, brinquedos, cadernos e canetas, livros, dentre outros, podem usufruir de uma produção de sucesso para aumentar a divulgação e venda de seus produtos.

Citamos também como fonte de receita o product placement (colocação de produto), que consiste "na inserção de uma marca ou produto dentro de um programa (LAFUENTE, 2016)", visando um aumento da divulgação e popularidade do produto, resultando em maiores vendas. Podemos ver claros exemplos desta técnica em filmes que divulgam marcas de refrigerantes, restaurantes, carros e eletrônicos, dentre outros. Product placement no Brasil é normalmente responsável por $10-20 \%$ do orçamento de produções que trabalham com esta técnica. Nos Estados Unidos, esse percentual é significativamente maior (ARBEX, 2007, p. 65).

\subsection{Estudo de Viabilidade Econômico-financeira}

Para decidir a respeito da viabilidade de um projeto ou negócio, um estudo é feito a partir de indicadores financeiros.

Indicadores econômico-financeiros são os elementos que tradicionalmente representam o conceito de análise de balanço. São cálculos matemáticos efetuados a partir do balanço patrimonial e da demonstração de resultados, procurando números que ajudem no processo de classificação do entendimento da situação da empresa, em seus aspectos patrimoniais, financeiros e de rentabilidade. (PADOVEZE, 2010, p. 213). 
Para entendermos a viabilidade econômico financeira de um projeto, podemos utilizar três indicadores de grande utilidade. São estes VPL, TIR e Payback.

O valor presente líquido (VPL), é uma fórmula usada para determinar a viabilidade de um investimento. É calculado a partir dos fluxos estimados de caixa de um projeto. Os fluxos de caixa, são descontados utilizando-se uma taxa, e levando em consideração a duração do investimento. Após o desconto, são somados todos os fluxos de entrada e saída de caixa, resultando no valor presente líquido da operação (Cavalcante, 2017).

A "taxa dada" no VPL, é o custo de capital do investidor, ou seja, a rentabilidade que o investidor espera adquirir do projeto, levando em consideração a indústria na qual o investimento se situa, bem como o risco percebido do investimento.

Após os fluxos de caixa serem descontados, e somados com o investimento inicial, obtemos um valor positivo ou negativo de VPL. Um valor negativo representa que o retorno obtido nos fluxos é menor do que o investimento inicial na taxa dada, e portanto o projeto, neste aspecto, não apresenta viabilidade. Um valor positivo significa que os fluxos descontados a taxa e somados, é maior do que o investimento inicial, e portanto, o projeto apresenta viabilidade para o investidor. A formula para cálculo do VPL pode ser resumida abaixo:

$$
\begin{aligned}
& \text { Fórmula } 1 \text { - Cálculo do } \mathrm{VPL} \\
& \qquad V P L=\sum_{t=0}^{n} \frac{F C_{t}}{(1+i)^{\mathrm{t}}} \quad \begin{array}{l}
\mathrm{t}=\text { período (anos ou meses) } \\
\mathrm{n}=\text { tempo total projeto (anos ou meses) } \\
\mathrm{i}=\text { taxa mínima de atratividade (TMA) } \\
\mathrm{FC}=\text { fluxo caixa por período }
\end{array}
\end{aligned}
$$

Fonte: https://evertongomede.blogspot.com.br/2011/06/analise-de-viabilidade-economico.html

Para melhor entender o "i"/Taxa mínima de atratividade, o mínimo que um investidor espera receber pelo seu investimento, é importante entender o conceito CAPM, ou Capital Asset Pricing Model. Este é um modelo utilizado para determinar a taxa esperada de retorno de um investimento. Sua fórmula, da qual existem algumas variações, pode ser encontrada abaixo. 
Formula 2 - Cálculo da CAPM

\section{CAPM}

\section{$R s=\operatorname{Rf}+\beta(\operatorname{Rm}-\mathrm{Rf})$}

Fonte: https://pt.slideshare.net/MerrySaimRaja/capm-theory-52702877

Tabela 2 - Composição da CAPM

\begin{tabular}{|l|l|}
\hline Rs & Retorno esperado do ativo \\
\hline $\mathrm{Rf}$ & Retorno obtido em investimento de risco mínimo (ex. taxa SELIC ou T-bill) \\
\hline $\boldsymbol{\beta}$ & Uma medida de risco sistemático para indústrias \\
\hline $\mathrm{Rm}$ & Retorno esperado do mercado \\
\hline
\end{tabular}

Fonte: Phillip Cattley (2017)

No que diz respeito a capital incentivado e CAPM, é importante fazer uma observação. O uso de capital incentivado, livre de risco e obrigações, reduz drasticamente o risco percebido pelo investidor. Isso faz com que a TMA do projeto seja reduzida, e que o VPL cresça, aumentando as chances de viabilidade de um projeto. Este estudo contempla o uso do modelo CAPM tradicional, porém, uma simulação do modelo CAPM, que utiliza uma média ponderada de custo de capital: uma taxa de 7\% (SELIC) para capital incentivado e17,14\% para capital próprio, pode ser encontrada no Anexo 8. Podemos então apreciar a diferença que um menor custo de capital tem sobre o VPL de um projeto.

O segundo indicador financeiro utilizado é a TIR, ou Taxa Interna de Retorno. O propósito da TIR, é o de encontrar a taxa de desconto que faça com que o investimento inicial seja pago (Cavalcante, 2017). Podemos entender a formula da Taxa Interna de Retorno como sendo:

Fórmula 3 - Cálculo da Taxa Interna de Retorno

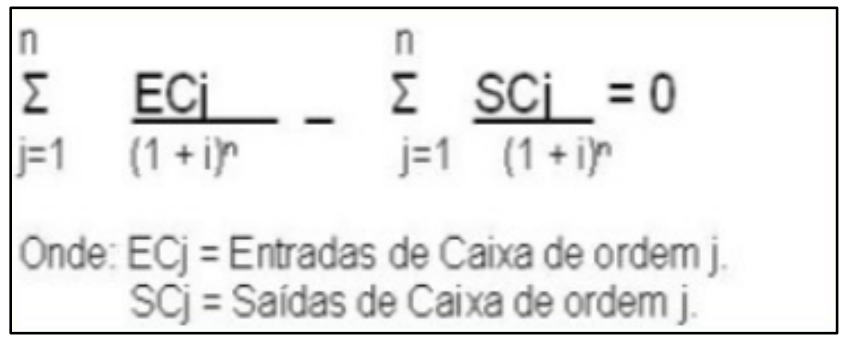

Fonte: http://slideplayer.com.br/slide/1739494/ 
Entendendo que a soma das entradas de caixa, a um valor negativo das saídas de caixa, deve resultar em zero. Para que um investimento seja viável, é importante que seu custo de capital, ou taxa mínima de atratividade, seja menor do que a TIR apresentada.

O terceiro e último indicador utilizado será o período de Payback Descontado. Este se refere à quantidade de tempo necessária para que um projeto retorne, em fluxos de caixa descontados a custo de capital, o valor inicial investido. Pode ser particularmente útil utilizar o payback descontado no que se diz respeito a filmes, dada a longa natureza do investimento. Por conseguinte, sua fórmula será exposta neste estudo da seguinte forma:

Fórmula 4 - Payback Descontado

Payback Descontado $=\frac{\text { Investimento Inicial }}{\text { Entradas de Caixa Descontadas }}$

Fonte: Phillip Cattley

Os três indicadores supracitados nos capacitam a melhor compreendermos a viabilidade de se investir em filmes. Contudo, antes de assumirmos determinado projeto, é importante nos atentarmos a quais são os riscos associados ao investimento, visto que estes impactam diretamente sobre a decisão final do investidor, e nem sempre são evidentes.

\subsection{Riscos na Produção de Filmes}

Podemos dizer que todo investimento tem riscos (FINRA, 2017), sendo estes ampliados pela falta de conhecimento do investidor (SNYDER, 2017). Entretanto, existem alguns riscos inerentes a investimentos em filmes, que não estão necessariamente presentes em outros projetos. É importante que o investidor considere todos estes antes de escolher onde alocar seus recursos.

Imprevisibilidade: diferente, por exemplo, de um contrato de venda de energia para uma distribuidora, onde quem produz tem a segurança de que existe demanda para a produção, e que seu produto será vendido, filmes apresentam 
imprevisibilidade. Um filme pode ser composto por um grande elenco, com renomados atores, produtores, compositores e diretor, porém a participação destes em uma produção não é garantia que a mesma terá sucesso de bilheteria (REILLY, 2015). A subjetividade da apreciação e a variabilidade de gostos também podem contribuir para o fracasso de uma produção, visto que tendências que antes faziam sucesso, eventualmente não terão o mesmo apelo.

Longa duração dos investimentos - atrasos: O tempo de produção de um filme varia, com base em um grande número de fatores, incluindo o gênero e o tamanho do próprio. No processo de pré-produção, quando um cronograma é elaborado, produtores podem prever um grande número de fatores e planejar contingências para evitar que problemas impeçam o processo de filmagem. Todavia, existem alguns fatores que não podem ser previstos com grande certeza, tornando o processo todo de filmagem potencialmente arriscado e mais custoso. O clima é inconsistente, fazendo com que a filmagem seja suspensa enquanto condições de tempo sejam adversas. Condições ruins de tempo também contribuem para que os salários de horistas aumentem, bem como custos de locação, transporte, alimentação, dentre outros. Qualquer dano feito a equipamentos durante viagens também precisa ser considerado, visto que muitos filmes utilizam câmeras e microfones alugados, de custo elevado.

Pirataria: Uma pesquisa realizada pela empresa de software Mark Monitor, constatou que o Brasil é o quarto país que mais pirateia filmes na internet (Olhar Digital, 2014), prejudicando a indústria e tornando a viabilidade de projetos de filmes ainda mais arriscados. 


\section{Métodos e procedimentos de coleta e de análise de dados do estudo}

\subsection{Estratégia de investigação OU Metódo de pesquisa utilizado}

O processo de investigação foi realizado em duas principais etapas, quais sejam: (I) a coleta de dados do mercado audiovisual, incluindo mecanismos, incentivos, custos, além das práticas da indústria que determinam a divisão de lucro entre os sócios de um projeto cinematográfico. (II) Dados específicos de projetos, incluindo orçamentos, receitas de bilheteria, patrocínios, investimentos e impostos. A coleta de dados de mercado foi realizada na Agência Nacional de Cinema (Ancine), com a ajuda da Coordenação de Análise de Direitos. Um roteiro de entrevista informal foi preparado, com perguntas abertas, que visavam situar o autor na indústria de filmes brasileira. Uma segunda entrevista, de caráter informal e sem roteiro definido foi realizada com um profissional da indústria, para melhor entender o papel de incentivos fiscais no processo de financiamento de filmes, bem como a função da distribuidora na indústria de filmes brasileiros. A segunda etapa foi principalmente realizada através de livros, artigos acadêmicos e sites da internet. A partir dos resultados, um estudo foi desenvolvido com indicadores financeiros para demonstrar a viabilidade dos projetos estudados de acordo com os critérios de VPL, TIR e Payback. Conclusões foram baseadas na pesquisa realizada ao longo do projeto, e os resultados obtidos através dos indicadores financeiros.

\subsection{Fontes de informação selecionadas para coleta de dados no estudo}

O estudo tem como foco três produções cinematográficas nacionais, de autores, produtores, diretores e elenco diferentes, escolhidas aleatoriamente, porém dentro de um padrão comum. O orçamento dos filmes pesquisados foi 
limitado a U\$2,190,000.00, entendendo que a média orçamentaria de filmes nacionais é de $R \$ 7,000,000.00$ (I). Estas produções apresentam diferentes estruturas de capital podendo ser compostas de capital majoritariamente incentivado, privado ou misto. Para adquirir os números utilizados na construção do modelo CAPM, utilizado para definir o custo de capital do projeto, os websites da NYU/Damodaran e MarketWatch foram consultados.

\subsection{Procedimentos e instrumentos de coleta de dados utilizados no estudo}

A coleta de dados utilizados no estudo foi feita com base nas entrevistas mencionadas, a primeira na Coordenação de Análise de Direitos da Ancine, a segunda, com um profissional da área de distribuição de filmes. A biblioteca da Ancine também foi consultada, e auxiliou, disponibilizando artigos acadêmicos e websites que pudessem apoiar o estudo. A partir das informações coletadas, artigos acadêmicos de tópicos relacionados a filmes, bem como sites de notícias e entrevistas, websites com dados do mercado financeiro e relatórios disponibilizados pela Ancine foram consultados. Estes foram principalmente utilizados para 0 referencial teórico do estudo. O website BoxOfficeMojo, subsidiário da IMDB/Amazon, foi particularmente importante para obter informações relacionadas à bilheteria de filmes. O livro "Film Business: O negócio do Cinema" também foi de grande importância para o desenvolvimento do estudo.

\subsection{Formas de tratamento e análise dos dados coletados para o estudo}

Os dados obtidos na entrevista informal realizada na Ancine, e com o professional da área de distribuição foram captados e estudados, e foram a base do referencial teórico e do estudo dos indicadores financeiros. A partir da elaboração dos indicadores financeiros, observações puderam ser feitas a respeito da viabilidade de projetos de filme, e do cenário atual da indústria de filmes brasileiros. Estas observações foram então estudadas, no contexto do projeto como um todo, para formar uma conclusão, que busca informar o investidor potencial a respeito da viabilidade de filmes brasileiros. 


\section{Apresentação e análise dos resultados}

\subsection{Os Filmes}

Três projetos cinematográficos foram escolhidos para serem estudados. Como relatado, estes projetos foram escolhidos de maneira aleatória, tendo somente em comum um valor orçamentário aproximado, este não podendo superar $R \$ 7,000,000.00$ ou $\$ 2,190,000.00$. Os três filmes estudados foram Aquarius (2016), 2 Coelhos (2012), e O Shaolin do Sertão (2016).

É de importância para o leitor, mencionar que existe confidencialidade acerca dos dados financeiros de produções cinematográficas nacionais, dado o seu valor estratégico para produtoras, distribuidoras e exibidoras. Informações, como o mês de captação de recursos, ou o percentual de lucro auferido ao produtor em suas negociações com o distribuidor e exibidor não puderam ser obtidas, e portanto foram estimadas. O mês de captação de recursos apresentado, necessário para cálculos financeiros, é o mês prévio ao começo das filmagens. Esta estimativa compreende que existe valor do dinheiro ao longo do tempo, e que investidores evitam deixar seu capital fora de aplicações rentáveis, preferindo alocar seus recursos somente no momento necessário, assim maximizando seu lucro. No que se diz respeito ao percentual de bilheteria negociado para o produtor, foi utilizada uma regra informal de mercado, onde $50 \%$ dos lucros são repassados ao exibidor, sendo a outra metade repartida a proporção respectiva de $30 \%$ e $70 \%$ entre o distribuidor e o produtor (STERNHEIM, 2013), auferindo ao último um percentual de $37,5 \%$ dos lucros totais de bilheteria. É importante mencionar que lucros obtidos pela venda de títulos de DVD/Blu-Ray, bem como lucros provenientes de contratos de exibição para TV e serviços de demanda não foram incluídos no estudo por motivos de acessibilidade de dados. Não obstante, para o investidor, é importante entender que esta fonte de lucro, embora secundária, aumenta o VPL/TIR dos projetos, e diminui o 
payback descontado, tornando-os mais atrativos. Os artigos específicos de medidas de incentivo foram incluídos quando disponíveis. Percentuais e prazos negociados entre a produtora e financiadores através de certificados de investimento, para o filme: "O Shaolin do Sertão" não puderam ser obtidos, porém é importante lembrar que filmes que optam por captar financiamento na forma de certificados de investimento distribuem um percentual de seus lucros para investidores ao longo de um prazo negociado. Por esse motivo, o VPL e TIR destes projetos podem sofrer alterações (Banestes, 2015). A taxa de desconto dos projetos, baseada na CAPM, foi convertida de anual para mensal com fins de oferecer um resultado mais preciso da rentabilidade dos projetos em questão. O valor dos orçamentos, receitas, patrocínios foram calculados a partir da taxas de câmbio dos respectivos períodos. Finalmente, $5 \%$ de ISS, imposto sobre serviços, foi calculado para cada projeto estudado (BARBOSA, 2017, p. 173).

\subsection{Descrição dos resultados}

Os três projetos estudados, embora de tamanho semelhante, apresentaram resultados distintos.

\subsubsection{Filme: Aquarius}

Quadro 1 - Resultados do Filme: Aquarius

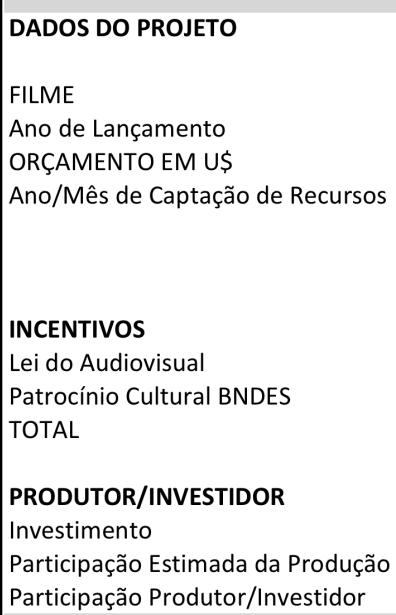

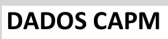


O filme premiado, Aquarius, lançado em 2016, teve o menor orçamento dos projetos estudados $(\$ 1.011 .904,76)$. No que se diz respeito a composição do orçamento, podemos dizer que o filme foi inteiramente financiado com capital incentivado, sendo este pela Lei do Audiovisual, e por patrocínio cultural do BNDES. Os produtores/investidores no caso, obtiveram estimados $37,5 \%$ da receita de bilheteria do filme, além das participações negociadas para DVD/Blu-ray. O filme obteve um fluxo descontado de bilheteria de $\$ 1.887 .991,76$, com impostos de $5 \%$ inclusos no cálculo. Apresentou um VPL positivo, de $\$ 672.597,06$. Por ter tido seu financiamento patrocinado, não apresentou uma taxa interna de retorno. Porém, uma simulação foi feita com investimento simbólico, gerando um valor de TIR expressivo. Esta simulação pode ser apreciada no Anexo 2. Finalmente, por se considerar um projeto de financiamento patrocinado, o período de payback descontado pode ser considerado 0.

\subsubsection{Filme: 2 Coelhos}

\section{Quadro 2 - Resultados do Filme: 2 Coelhos}
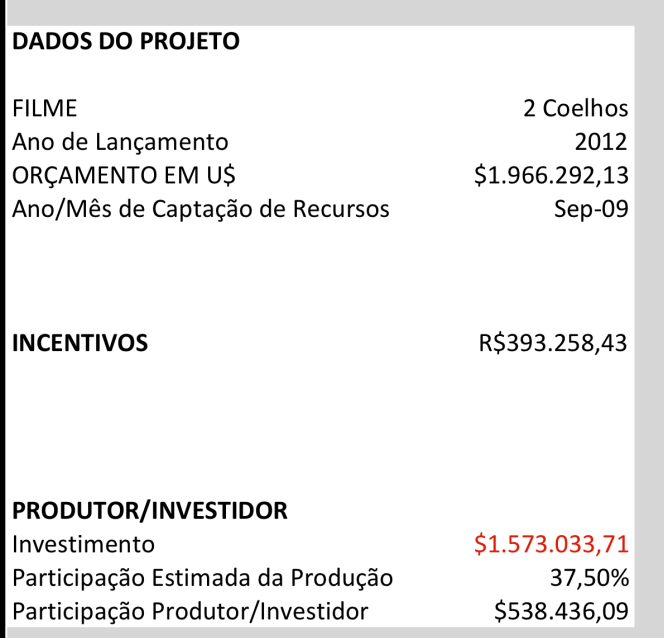

\section{DADOS CAPM}

RF (10 Year T-Bill)

Emerging Market Entertainment Beta

Equity Risk Premium Brazil

Country Risk Premium Brazil

CAPM

Taxa Mensal

O filme de ação, 2 Coelhos, lançado em 2012, teve orçamento de $\$ 1.966 .292,13$. O filme teve dificuldades em conseguir arrecadar fundos em um curto prazo de tempo, e por isso, investidores optaram por investir $80 \%$ do capital requerido para orçamento, recorrendo a leis de incentivo para arrecadar os $20 \%$ que faltavam. Os produtores/investidores, obtiveram estimados $37,5 \%$ da receita de 
bilheteria do filme, além das participações negociadas para DVD/Blu-ray. O filme apresentou um fluxo descontado de bilheteria de $\$ 1.511 .399,55$, já inclusos os impostos descontados. O VPL apresentado foi, surpreendentemente negativo, de $\$ 1.034 .597,62$, e a taxa interna de retorno ficou em $-24,33 \%$. Visto que não ocorre a recuperação do investimento, não existe payback. Porém, é importante lembrar que o estudo não compreende fontes adicionais de receita, e que é possível que o filme "2 Coelhos" tenha recuperado o capital investido através destas fontes.

\subsubsection{Filme: O Shaolin do Sertão}

Quadro 3 - Resultados do Filme: O Shaolin do Sertão

\begin{tabular}{|c|c|c|c|}
\hline \multicolumn{2}{|l|}{ DADOS DO PROJETO } & \multicolumn{2}{|l|}{ DADOS CAPM } \\
\hline FILME & O Shaolin do Sertão & RF (10 Year T-Bill) & $2,39 \%$ \\
\hline Ano de Lançamento & 2016 & Emerging Market Entertainment Beta & 1.12 \\
\hline ORÇAMENTO EM U\$ & $\$ 1.818 .181,82$ & Equity Risk Premium Brazil & $9,64 \%$ \\
\hline \multirow[t]{3}{*}{ Ano/Mês de Captação de Recursos } & Jun-14 & Country Risk Premium Brazil & $3,95 \%$ \\
\hline & & CAPM & $17,14 \%$ \\
\hline & & Taxa Mensal & $1,33 \%$ \\
\hline INCENTIVOS & & RESULTADOS & \\
\hline Incentivos Culturais (Lei 8.685/93) & $\$ 327.272,73$ & FLUXO DESCONTADO TOTAL & $\$ 2.321 .923,59$ \\
\hline Incentivos Culturais (Artigo 3A) & $\$ 750.000,00$ & IMPOSTOS (ISS) & $\$ 116.096,18$ \\
\hline TOTAL & $\$ 1.077 .272,73$ & TOTAL & $\$ 2.205 .827,41$ \\
\hline \multicolumn{4}{|l|}{ PRODUTOR/INVESTIDOR } \\
\hline Investimento & $\$ 740.909,09$ & VPL & $\$ 86.276,19$ \\
\hline Participação Estimada da Produção & $37,50 \%$ & TIR & $25,38 \%$ \\
\hline Participação Produtor/Investidor & $\$ 827.185,28$ & Payback Descontado & 2 anos e 4 meses \\
\hline
\end{tabular}

Fonte: Phillip Cattley (2017)

O Shaolin do Sertão, uma comédia/aventura lançada em 2016, teve o segundo maior orçamento dos três filmes estudados, com $\$ 1.818 .181,82$. O filme teve cerca de $60 \%$ de seu orçamento coberto por incentivos culturais, onde empresas puderam, através da compra de certificados, exibir sua marca no filme. Os produtores/investidores, obtiveram estimados $37,5 \%$ da receita de bilheteria do filme, além das participações negociadas para DVD/Blu-ray. O fluxo de bilheteria apresentado foi de $\$ 2.321 .923,59$, descontados os $5 \%$ de ISS. O VPL foi positivo, a TIR foi de 25,38\%, e o payback descontado do filme foi de 2 anos e 4 meses. 


\subsection{Análise dos resultados}

Nesta parte do estudo, analisaremos os filmes estudados, incluindo fatores que possam ter contribuído para um resultado positivo ou negativo.

\subsubsection{Análise: Aquarius}

Aquarius representa, possivelmente, um dos melhores cenários que um investidor/produtor de filmes pode esperar. Seu orçamento é menos da metade da média de filmes produzidos hoje ( $R \$ 3,4 \mathrm{M}$ comparados a $R \$ 7 M)$, seu sucesso foi internacional, vencendo 40 prêmios no Brasil e afora, sendo indicado para a honrosa Palma de Ouro em Cannes. O sucesso de bilheteria, que foi exibido em 12 países (Anexo I), teve um fluxo descontado total, após o pagamento de impostos, $87 \%$ superior a seu orçamento. Não obstante o sucesso acima relatado, que não inclui o cálculo de títulos de Blu-ray/DVD e vendas para serviços de demanda, ou prêmios de incentivo concedidos pela ANCINE (PAR e PAQ), o maior atrativo para o possível investidor ou produtor é outro. O projeto foi feito exclusivamente com recursos incentivados. Para o investidor, é importante obter-se "capital barato", ou capital com juros baixos para aumentar a rentabilidade do investimento. Capital incentivado, no entanto, diminui o risco consideravelmente, podendo em casos, anular o mesmo. $O$ investidor/produtor então, é alavancado e protegido de risco, sendo sua taxa interna de retorno aumentada consideravelmente. No exemplo de Aquarius, um valor simbólico de $\$ 1$ investido, obteve uma TIR de $7.842 .612 \%$ e um VPL positivo, de $\$ 672.597,06$. Os produtores tiveram um período de payback descontado igual a zero, visto que nenhum recurso foi aplicado. Para investigar o impacto que a fonte de financiamento, recursos incentivados, teve na rentabilidade de Aquarius, um cenário foi simulado onde o orçamento incentivado foi substituído por capital próprio. Os resultados apresentaram grande diferença de rentabilidade. O VPL, antes positivo passou para $-\$ 339.307,70$ (Anexo 2), enquanto a TIR, também negativa, ficou em $-11,1 \%$. Foi calculado que, caso o investidor quisesse obter um retorno igual a ou superior a taxa de $17,14 \%$ (TMA do projeto), não poderia investir um valor superior a $\$ 709.000,00$ (aproximadamente $70 \%$ do valor total de orçamento). Não obstante o segundo cenário, podemos concluir que o projeto original foi bem sucedido, atendendo bem aos resultados de VPL, TIR e payback descontado. Os anexos I e 2 podem ser consultados para mais informações. 


\subsubsection{Análise: 2 Coelhos}

O filme de ação 2 Coelhos, recebeu excelentes críticas (DIDIMO, 2012), e foi bem recebido pelo público brasileiro, que elogiou o estilo criativo do diretor Afonso Poyart, bem como as ousadas cenas de ação. Não obstante a boa recepção recebida, o filme apresentou, como veremos, uma rentabilidade muito diferente de Aquarius. Para começar, o filme não obteve o mesmo impacto internacional do projeto anterior, tendo tido suas receitas de bilheteria restritas ao território nacional. A bilheteria nacional foi $11 \%$ maior do que o orçamento do filme, um número pouco expressivo, enquanto o fluxo descontado do projeto foi menor do que o orçamento em 27\%. O filme pode ter obtido sucesso significativo com a venda de BluRays/DVDs e a venda dos direitos de exibição para canais de TV, porém no que diz respeito a receita de bilheteria, não obteve grande sucesso. Em relação ao financiamento do filme, somente $20 \%$ do capital utilizado foi incentivado, tendo o produtor investido os outros $80 \%$ utilizando seu próprio capital. O diretor do filme, Afonso Poyart relata:

Sou meio ansioso e resolvi começar logo, com nosso dinheiro mesmo. Só que a gente queria captar no meio do caminho e repor o caixa. É possível isto, ou nos disseram que era possível. Não aconteceu, acabamos captando pouco, apenas cerca de $20 \%$ do orçamento estimado. Então usamos dinheiro próprio, ao invés de incentivado. O que foi muito difícil, isto nos colocou em uma posição bem frágil (Wikipédia, 2017).

O filme não obteve bons resultados financeiros, com VPL negativo de $\$ 1.034 .597,62$, e uma TIR de $-24,33 \%$. Isto pode ser explicado ao lembrarmos de que, de toda receita acumulada na bilheteria de um filme, somente cerca de $37,5 \%$ são destinadas a produção, sendo grande parte retida pelo exibidor. Um filme como 2 Coelhos, que obteve receita razoável, precisaria ter tido um sucesso muito maior de vendas para compensar os $\$ 1.573 .033,71$ investidos pelo produtor na época. Com somente $20 \%$ de capital incentivado, os ganhos de bilheteria precisariam ser de no mínimo $\$ 11.190 .000,00$ para obter-se um VPL positivo, uma receita que representa mais de cinco vezes a original de $\$ 2.187 .985,71$. Alternativamente, o projeto poderia ter aumentado o seu uso de capital incentivado. Ao investir não mais 
do que $\$ 567.000,00$ (29\% do orçamento total), o investidor honraria a sua TMA de $17,14 \%$ e alcançaria um VPL positivo. O payback descontado do filme não foi atingido no cenário estudado, sendo estimado em superior a 2 anos e 4 meses. Porém, o cenário não contempla vendas de Blu-Ray/DVDs e receitas de direitos de exibição do produto. O cenário também não contempla diferentes margens de negociação entre produtor/distribuidor/exibidor, que também podem ter um grande efeito na quantidade de tempo que um projeto demora para retornar seu investimento. Não obstante, no cenário estudado, o projeto não obteve o retorno financeiro esperado. Os anexos 3 e 4 podem ser consultados para mais informações.

\subsubsection{Análise: O Shaolin do Sertão}

Para concluir, O Shaolin do Sertão. Um filme de comédia/ação, que obteve grande sucesso nacional, tendo atingido mais de 500,000 espectadores em todo o país (ROCHA, 2016). Sua bilheteria foi um sucesso, tendo superado seu orçamento em $27 \%$. No que se diz respeito a financiamento, o filme encontra-se exatamente entre Aquarius (que teve todo o seu orçamento incentivado), e 2 Coelhos (que contou com $20 \%$ de orçamento incentivado), tendo tido $\$ 1.077 .272,73$ (60\% de seu orçamento) patrocinado. Obteve um VPL positivo de $\$ 86.276,19$ e uma TIR acima de sua taxa mínima de atratividade (25,38\%). O payback descontado foi de 2 anos e 5 meses, menor do que 2 Coelhos, porém significativamente maior do que Aquarius, tornando o investimento, comparativamente longo. Para novamente investigar o impacto que o financiamento incentivado tem na rentabilidade do projeto, podemos simular o financiamento do filme com 100\% de capital próprio, obtendo: um VPL negativo de $-\$ 990.996,54$, e uma TIR de $-14,06 \%$, novamente comprovando a importância da utilização de capital incentivado para a rentabilidade de filmes. É importante novamente lembrar que este projeto foi financiado em parte com certificados de investimento, e portanto, precisará devolver dividendos aos seus financiadores. Porém, no presente cenário, pode se dizer que o filme "O Shaolin do Sertão" foi bem sucedido no que se diz respeito aos três indicadores (VPL, TIR, Payback descontado), e apresenta viabilidade para o investidor. Para mais informações, os anexos 5 e 6 podem ser consultados. 


\section{Conclusões e recomendações para novos estudos}

Podemos concluir este estudo entendendo que filmes brasileiros podem ser, não somente viáveis, mas também extremamente rentáveis. Porém, como em qualquer projeto, existem riscos inerentes, e medidas que precisam ser tomadas para minimizar este risco e aumentar a lucratividade do negócio. Este capítulo propõem-se resumir o conteúdo aprendido pelo autor ao longo do estudo, identificando os principais elementos que contribuem para a viabilidade de filmes brasileiros e sugerindo como estes podem ser abordados para aumentar as chances de sucesso de projetos no futuro.

Para começar, é importante lembrar que existe demanda, e que a indústria brasileira de filmes cresce. Filmes brasileiros têm tido maior presença, não somente em território nacional, mas também no mercado internacional. O cenário é favorável para investimentos, quais projetos, então, apresentam viabilidade?. Podemos começar abordando a questão de receita.

Os três projetos de filmes estudados, obtiveram receitas maiores do que seus orçamentos. Para se ter receita, é importante que exista qualidade percebida no produto ou serviço, e que exista ampla divulgação desta qualidade. Para um projeto de filme, a qualidade percebida esta no roteiro, direção, elenco e equipe técnica. Considera-se então fundamental o investimento na elaboração/aquisição de um roteiro e de pessoas que atraiam o público para o cinema, e aumentem o valor da receita. Aquarius, atraiu estimados 500,000 espectadores no Brasil e afora (Wikipédia, 2017), O Shaolin do Sertão atraiu um número semelhante (ROCHA, 2016), e 2 Coelhos contou com mais de 247,000 (Wikipédia, 2017) espectadores. É importante lembrar que, como foi o caso de Aquarius, uma produção não esta restrita ao público nacional, podendo também auferir lucros no exterior (cerca de $50 \%$ da receita de bilheteria de Aquarius, disponível no Anexo I, foi internacional). No que se diz respeito a receita, também é importante lembrar que, no Brasil, o produtor precisa dividir grande parte de seu lucro de bilheteria com o cinema 
(exibidor) e o distribuidor. O processo de negociação entre o produtor e as demais partes é portanto extremamente importante para a maximização de receita, e viabilidade do projeto como um todo. Em suma, no que se diz respeito a receita, um filme precisa (I) investir em roteiros, elencos e equipes de qualidade, (II) explorar oportunidades no mercado internacional e (III) negociar margens rentáveis com seus distribuidores e exibidores para potencializar as chances de viabilidade.

Não obstante a importância da receita, um filme não será viável caso apresente um custo que exceda esta receita. É portanto muito importante que a fase de préprodução seja planejada e executada de forma a manter o filme dentro de seu orçamento, e reduzir ao máximo os custos incorridos no projeto sem comprometer a qualidade final do filme. É válido lembrar que os processos de produção e lançamento de um filme contem riscos inerentes, alguns dos quais: pirataria, má recepção/críticas, adversidades no set de filmagem, não poderão ser evitados, e serão fonte de despesa. Os custos que puderem ser controlados então, devem ser, através do estabelecimento e cumprimento de um cronograma eficiente na etapa da pré-produção. Um cronograma eficiente compreende também a utilização ótima de capital, ou seja o capital do investidor não deve ficar fora de aplicações rentáveis, devendo ser requisitado somente quando necessário. É importante também apontar que um grande orçamento não necessariamente se traduz em maiores receitas, e que no estudo realizado com três filmes, o projeto de menor orçamento obteve o maior retorno (Aquarius).

Talvez um dos aspectos mais determinantes na viabilidade de filmes é o custo de capital. Como vimos na parte de análise dos resultados, é de interesse para o investidor obter capital com juros baixos para financiar seus projetos. $\mathrm{Na}$ indústria de filmes, existe grande repartição da receita, o que afeta drasticamente a viabilidade de projetos de filme. O capital barato, torna-se então essencial para o sucesso do projeto, sem o qual, como foi demonstrado pela análise dos três filmes estudados, projetos tornam-se inviáveis. As fontes de capital que podem ser empregadas em filmes, e que apresentam menor custo para o investidor, ou maior rentabilidade, são aquelas provenientes de patrocínios. 
Através de um patrocínio, uma empresa pode, com recursos de renúncia fiscal, exibir sua marca em um filme. Para os produtores do filme, isto significa a detenção completa dos direitos comerciais da obra, o que eleva a rentabilidade do projeto como um todo. Adicionalmente, o risco do projeto cai a medida que patrocínios substituem capital próprio, o que também apresenta uma grande vantagem para o investidor. Patrocínios podem advir de instituições privadas/governamentais, como podem ser feitas através das leis Rouanet ou Lei do Audiovisual, e representam o método menos custoso, e logo mais rentável (junto a prêmios de desempenho e product placement), de se produzir um filme.

Prêmios de desempenho, como PAQ e PAR, também são consideradas excelentes opções para financiamento, visto que o capital premiado não precisa ser retornado para a agência emissora, sendo somente necessária sua aplicação em algum projeto. Financiamento por product placement, segue características semelhantes ao patrocínio, sendo considerado também um investimento em imagem na parte da marca. Difere principalmente do patrocínio no estilo de propaganda empregada, porém também não apresenta custos de juros para o projeto, ou requer a devolução do capital aplicado.

Como segunda preferência para a obtenção de capital, podemos citar certificados de investimento, que são vinculados a quotas de direitos de comercialização do filme. Embora estes reduzam o risco do projeto como um todo, requerem o pagamento de parcela dos lucros na parte do produtor. O fato desta parcela, naturalmente, já ser repartida entre produção, distribuição e exibição, torna essa modalidade menos atraente para um projeto, instituindo a obrigação de pagamento de dividendos, e diminuindo a rentabilidade do projeto de filme como um todo. Por última opção, podemos considerar financiamento próprio. É considerada uma modalidade extremamente custosa de financiamento, carregando com si o risco de perda de capital, caso o projeto não seja bem sucedido. Ao verificar os anexos 2, 4 e 6, podemos constatar que existe um valor máximo de capital próprio que pode ser aplicado a cada um dos três projetos, sem que comprometa o atingimento da TMA de 17,14\%. Para "Aquarius" este valor é de $70 \%$ do orçamento, para "2 Coelhos", que obteve bilheteria significativamente menor, o valor é de $28 \%$ do orçamento, e para "O Shaolin do Sertão", o valor máximo é de 47\% do orçamento. 
Através desta amostra de projetos, podemos calcular uma média, e constatar, com base nos resultados obtidos, que não mais de $49 \%$ de capital próprio deva ser utilizado para financiar projetos de filme, (podendo uma estimativa mais conservadora sugerir $25 \%$ com base nos resultados de "2 Coelhos") preferindo-se sempre a utilização de capital incentivado, livre de risco e de obrigação de retorno.

\subsection{Sugestões e recomendações para novos estudos}

Esta seção sugere futuros estudos que possam, eventualmente, dar prosseguimento ao estudo aqui relatado.

Para começar, acredito ser de importância um estudo que compreenda a rentabilidade da venda de DVDs/Blu-Rays, bem como a rentabilidade da venda dos direitos de exibição para serviços on demand (Netflix, Net Now, GooglePlay, AppleTV, AmazonTV).

Acredito também ser de importância um estudo que analise o processo de captação de recursos como um todo, compreendendo a disponibilidade das fontes de recurso, proporcionando assim um entendimento mais objetivo para possíveis investidores.

Um estudo que investigue o impacto da técnica, bem como a disponibilidade de financiamento através de product placement, também seria útil para investidores, diretores, produtores e outros profissionais da indústria. 


\section{Referências Bibliográficas}

Adoro Cinema. 2 Coelhos - Bilheteria. 2017 Disponível em: <http://www.adorocinema.com/filmes/filme-202692/>. Acesso em: 25 de Outubro. 2017.

ALVARENGA, D. Fitch mantém Brasil abaixo do grau de investimento e reafirma perspectiva negativa. G1, 19 de mai. 2017. Disponível em: <https://g1.globo.com/economia/noticia/fitch-mantem-brasil-abaixo-do-grau-deinvestimento-e-reafirma-perspectiva-negativa.ghtml>. Acesso em: 13 de setembro de 2017.

ALVARENGA, D. Moody's muda perspectiva da nota do Brasil de estável para negativa. G1, 26 de mai. 2017. Disponível em: <https://g1.globo.com/economia/noticia/moodys-muda-perspectiva-da-nota-do-brasilde-estavel-para-negativa.ghtml>. Acesso em: 13 de setembro de 2017.

ALVARENGA, D., LAPORTA, T. S\&P mantém Brasil abaixo do grau de investimento e reafirma perspectiva negativa. G1, 15 de mar. 2017. Disponível em: <https://g1.globo.com/economia/noticia/sp-mantem-nota-do-brasil-e-reafirmaperspectiva-negativa.ghtml>. Acesso em: 13 de setembro de 2017.

ANCINE. ANCINE lança edital do programa ANCINE de Incentivo à Qualidade PAQ 2013. Rio de Janeiro, 2013 Disponível em: <https://ancine.gov.br/pt-br/salaimprensa/noticias/ancine-lan-edital-do-programa-ancine-de-incentivo-qualidade-paq2013>. Acesso em: 4 de Novembro. 2017.

ANCINE. Carta de Serviços - Mecanismos de Fomento. Rio de Janeiro, 2017 Disponível em: <https://cartadeservicos.ancine.gov.br/?pg=fomento>. Acesso em: 31 de Outubro. 2017. 
ANCINE. Fomento - PAQ. Rio de Janeiro, 2017 Disponível em: <https://www.ancine.gov.br/fomento/paq>. Acesso em: 4 de Novembro. 2017. ANCINE. Fomento - PAR. Rio de Janeiro, 2017 Disponível em: <https://www.ancine.gov.br/sites/default/files/par/PAR\%202013\%20ANEXO_1A\%20c alculo\%20produtora.pdf>. Acesso em: 4 de Novembro. 2017.

ARBEX, A. L. M., Cinema e publicidade: um diálogo possível e necessário. Juiz de Fora, 2007. 65 p. TCC (Bacharel em Comunicação Social) - Departamento de Comunicação Social: Universidade Federal de Juiz de Fora.

Associação Brasileira da Indústria Têxtil e de Confecção. Setor têxtil e de confecção aponta sinais positivos para 2017. Rio de Janeiro, 2017 Disponível

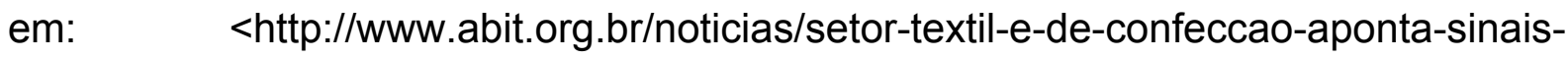
positivos-para-2017>. Acesso em: 13 de setembro. 2017.

Banco Central. Cotações e Boletins. 2017 Disponível em: <http://www4.bcb.gov.br/pec/taxas/port/ptaxnpesq.asp?id=txcotacao>. Acesso em: 09 de Novembro. 2017.

Banestes. Certificado de Investimento Audiovisual. 2015 Disponível em: <http://www.banestes.com.br/investimentos/invest_certificado_audiovisual.html>. Acesso em: 30 de Outubro. 2017.

BARBOSA, L., Film Business: O Negócio do Cinema. Rio de Janeiro: Elsevier, p. 173. 2017.

Box Office Mojo. Aquarius. Rio de Janeiro, 2017 Disponível em: <http://www.boxofficemojo.com/movies/?page=intl\&id=aquarius.htm>. Acesso em: 18 de Outubro. 2017.

Box Office Mojo. O Shaolin do Sertão. Rio de Janeiro, 2017 Disponível em: <http://www.boxofficemojo.com/movies/intl/?page=\&country=BR\&id=_fOSHAOLIND OSERTO01>. Acesso em: 18 de Outubro. 2017. 
Cavalcante. Taxa Interna de Retorno. São Paulo, 2017 Disponível em: <http://www.cavalcanteassociados.com.br/article.php?id=236>. Acesso em: 02 de Outubro. 2017.

Cavalcante. Valor Presente Líquido. São Paulo, 2017 Disponível em: <http://www.cavalcanteassociados.com.br/article.php?id=61>. Acesso em: 02 de Outubro. 2017.

COLLUSSO, L. C. O Produtor e o Processo de Produção de Filmes no Brasil . X Congresso de Ciências da Comunicação da Região Sul - Blumenau. Intercom Sociedade Brasileira de Estudos Interdisciplinares da Comunicação, 2009.

DIDIMO, D. 2 Coelhos (2012): ousadia e diversão na produção dirigida por Afonso Poyart. Cinema com Rapadura, 2012. Disponível em: <http://cinemacomrapadura.com.br/criticas/247172/2-coelhos-ousadia-e-diversao-naproducao-dirigida-por-afonso-poyart/>. Acesso em: 29 de outubro de 2017.

Dino. Segundo Anfavea, setor automotivo terá crescimento em 2017. EXAME, 25 nov. 2016. Disponível em: <https://exame.abril.com.br/negocios/dino/segundoanfavea-setor-automotivo-tera-crescimento-em-2017-shtml/>. Acesso em: 13 de setembro de 2017.

FINRA. The Reality of Investment Risk. 2017 Disponível em: <http://www.finra.org/investors/reality-investment-risk>. Acesso em: 02 de Outubro. 2017.

FORNAZARI, F. K. Instituições do Estado e políticas de regulação e incentivo ao cinema no Brasil: o caso Ancine e Ancinav. Revista de Administração Pública, v. 40, n.4, p. 658, 2006.

FSA. PRODECINE - Programa de Apoio ao Desenvolvimento do Cinema Brasileiro. Rio de Janeiro, 2017 Disponível em: <https://fsa.ancine.gov.br/programas/prodecine>. Acesso em: 26 de setembro. 2017. 
G1. Com 143 filmes, cinema brasileiro bate recorde de lançamentos em 2016. Rio de Janeiro, 2017 Disponível em: <https://g1.globo.com/poparte/cinema/noticia/com-143-filmes-cinema-brasileiro-bate-recorde-de-lancamentosem-2016.ghtml>. Acesso em: 12 de setembro. 2017.

GARRISON, Ray H., NOREEN, Eric W., BREWER, Peter C. Contabilidade Gerencial. 14 Edição, Amgh., 2013.

HESSEL, R. Cenário desolador nas fábricas: queda na produção passa de $60 \%$. Correio Braziliense, 24 abr. 2017. Disponível em: <http://www.correiobraziliense.com.br/app/noticia/economia/2017/04/24/internas_eco nomia,590501/queda-na-producao-passa-de-60-em-alguns-segmentos-industriaisno-pais.shtml>. Acesso em: 13 de setembro de 2017.

LAFUENTE, F., ZANONI, L., ALMEIDA, L. M., Red Bull, um estudo de caso de branded content. HSM Publishing, 15 fev. 2016. Disponível em: <http://www.revistahsm.com.br/marketing-e-vendas/red-bull-um-estudo-de-caso-debranded-content/>. Acesso em: 06 de novembro de 2017.

MarketWatch. U.S. 10 Year Treasury Note. Rio de Janeiro, 2017 Disponível em: <https://www.marketwatch.com/investing/bond/tmubmusd10y?countrycode=bx>. Acesso em: 22 de Outubro. 2017.

Michaelis. Dicionário Brasileiro da Língua Portuguesa - Receita. Rio de Janeiro, 2017 Disponível em: <http://michaelis.uol.com.br/busca?id=0LWao>. Acesso em: 27 de Setembro. 2017.

meio\&mensagem. Netflix: mais receita que SBT e mais assinantes que SKY. Rio de Janeiro, 2016 Disponível em: <www.meioemensagem.com.br>. Acesso em: 28 de Setembro. 2017. 
Melo, L. Os 10 filmes de maior bilheteria no Brasil em 2016 - até agora. EXAME, 29 dez. 2016. Disponível em: <https://exame.abril.com.br/negocios/os-10-filmes-demaior-bilheteria-no-brasil-em-2016-ate-agora/>. Acesso em: 14 de setembro de 2017.

OCA. Mercado Audiovisual Brasileiro. Rio de Janeiro, 2017 Disponível em: <https://oca.ancine.gov.br/mercado-audiovisual-brasileiro>. Acesso em: 28 de Setembro. 2017.

Olhar Digital. Brasil é $4^{\circ}$ em lista de pirataria de filmes na internet. 2014 Disponível em: <https://olhardigital.com.br/noticia/brasil-e-4-em-lista-de-pirataria-defilmes-na-internet/42706>. Acesso em: 02 de Outubro. 2017.

Bloc, A. Previsto para novembro, 'O Shaolin do Sertão' promove encontro de Ceará e China. O Povo, 14 jan. 2016. Disponível em: <https://www20.opovo.com.br/app/divirtase/2016/01/14/noticiasdivirtase,3561666/pre visto-para-novembro-o-shaolin-do-sertao-promove-encontro-de-cear.shtml>. Acesso em: 25 de outubro de 2017.

PADOVEZE, C. L., Contabilidade gerencial: um enfoque em sistema de informação contábil. São Paulo: Atlas, 2010. p. 213.

Portal da Indústria. Termômetro da Indústria: Pesquisa Industrial Mensal de Produção Física. Rio de Janeiro, 2017 Disponível em: <http://termometro.portaldaindustria.com.br/indicador/producao>. Acesso em: 13 de Setembro. 2017.

quero incentivar. Lei Rouanet. Rio de Janeiro, 2017 Disponível em: $<$ http://queroincentivar.com.br/leis-de-incentivo/lei-rouanet/>. Acesso em: 26 de Setembro. 2017.

quero incentivar. Lei do Audiovisual. Rio de Janeiro, 2017 Disponível em: $<$ http://queroincentivar.com.br/leis-de-incentivo/lei-rouanet/>. Acesso em: 26 de Setembro. 2017. 
REILLY, T., CUNNINGHAM, T., 41 A-List Actors who Bombed. The Wrap, 28 jan. 2015. Disponivel em: <https://www.thewrap.com/41-a-list-actors-who-bombed-ashard-as-johnny-depp-in-mordecai/> Acesso em: 02 de outubro de 2017.

ROCHA, L. O Shaolin do Sertão atinge meio milhão de espectadores e supera público de Cine Holliúdy. Tribuna do Ceara, 15 nov. 2016. Disponível em: $<$ http://tribunadoceara.uol.com.br/diversao/cinema/o-shaolin-do-sertao-atinge-meiomilhao-de-espectadores-e-supera-publico-de-cine-holliudy/>. Acesso em: 05 de novembro de 2017.

RODRIGUES, Chris. O cinema e a produção. 2. ed. Rio de Janeiro: Lamparina, 2007.(Página 68).

SALLES, F. Como se faz Cinema. mnemocine, 30 set. 2008. Disponível em: <http://www.mnemocine.com.br/index.php/downloads/doc_download/3-apendice-2etapas-da-producao-cinematografica>. Acesso em: 20 de setembro de 2017.

SEBRAE. O que são custos fixos e custos variáveis. Rio de Janeiro, 2016 Disponível em: <https://www.sebrae.com.br/sites/PortalSebrae/ufs/ap/artigos/o-quesao-custos-fixos-e-custos

variaveis,69cb1e2c6182c410VgnVCM1000003b74010aRCRD>.

Sensagent. Produção Cinematográfica. Disponível em: $<$ http://dicionario.sensagent.com/Produ\%C3\%A7\%C3\%A30\%20cinematogr\%C3\%A1 fica/pt-pt/>. Acesso em: 22 de setembro. 2017.

SIF-Ancine. Consulta de Projetos Audiovisuais. Rio de Janeiro, 2014 Disponível em:<http://sif.ancine.gov.br/projetosaudiovisuais/ConsultaProjetosAudiovisuais.do;js essionid=3E1D84BF68DEF0DD58D7EF389238C71D?method=detalharProjeto\&num Salic $=140233>$. 
SNYDER, B. 7 insights from legendar investor Warren Buffet. CNBC, 01 mai. 2017. Disponível em: <https://www.cnbc.com/2017/05/01/7-insights-from-legendaryinvestor-warren-buffett.html>. Acesso em: 02 de outubro de 2017.

Stern - NYU. Beta Emerging Markets. Rio de Janeiro, 2017 Disponível em: <www.stern.nyu.edu/ adamodar/pc/datasets/betaemerg.xls>. Acesso em: 22 de Outubro. 2017.

Stern - NYU. Country Default Spread and Risk Premiums. Rio de Janeiro, 2017 Disponível em: <http://pages.stern.nyu.edu/ adamodar/New_Home_Page/datafile/ctryprem.html>. Acesso em: 22 de Outubro. 2017.

STERNHEIM, A. O Orçamento e o faturamento dos filmes nacionais. GGN, 07 nov. 2013. Disponível em: <https://jornalggn.com.br/noticia/o-orcamento-e-ofaturamento-dos-filmes-nacionais>. Acesso em: 18 de outubro de 2017.

UFRGS. Incentivos Fiscais e Fomentos para Inovação. Rio de Janeiro, 2017 Disponível em: <https://www.ufrgs.br/icd/incentivos-fiscais-e-fomentos-parainovacao/>. Acesso em: 26 de Setembro. 2017.

Wikipédia. 2 Coelhos. Rio de Janeiro, 2017 Disponível em: <https://pt.wikipedia.org/wiki/2_Coelhos>. Acesso em: 25 de outubro. 2017.

Wikipédia. Aquarius (filme). Rio de Janeiro, 2017 Disponível em: $<$ https://pt.wikipedia.org/wiki/Aquarius_(filme)>. Acesso em: 14 de setembro. 2017.

Wikipédia. Financiamento de Empresas. Rio de Janeiro, 2017 Disponível em: <https://pt.wikipedia.org/wiki/Financiamento_de_empresas>. Acesso em: 26 de setembro. 2017. 
World Bank Group. Pesquisa de Crescimento Anual do PIB: indicadores 2015 e 2016. Rio de Janeiro, 2017 Disponível em: $<$ https://data.worldbank.org/indicator/NY.GDP.MKTP.KD.ZG?locations=BR>. Acesso em: 13 set. 2017.

ZAVERUCHA, V. Lei do Audiovisual Passo a Passo. ANCINE, 1996. Disponível em: <https://www.ancine.gov.br/sites/default/files/artigos/LEI_AUDIOVISUAL.pdf >. Acesso em: 26 de Setembro de 2017. 


\section{Anexo 1 - Fluxo descontado de bilheteria: Aquarius}

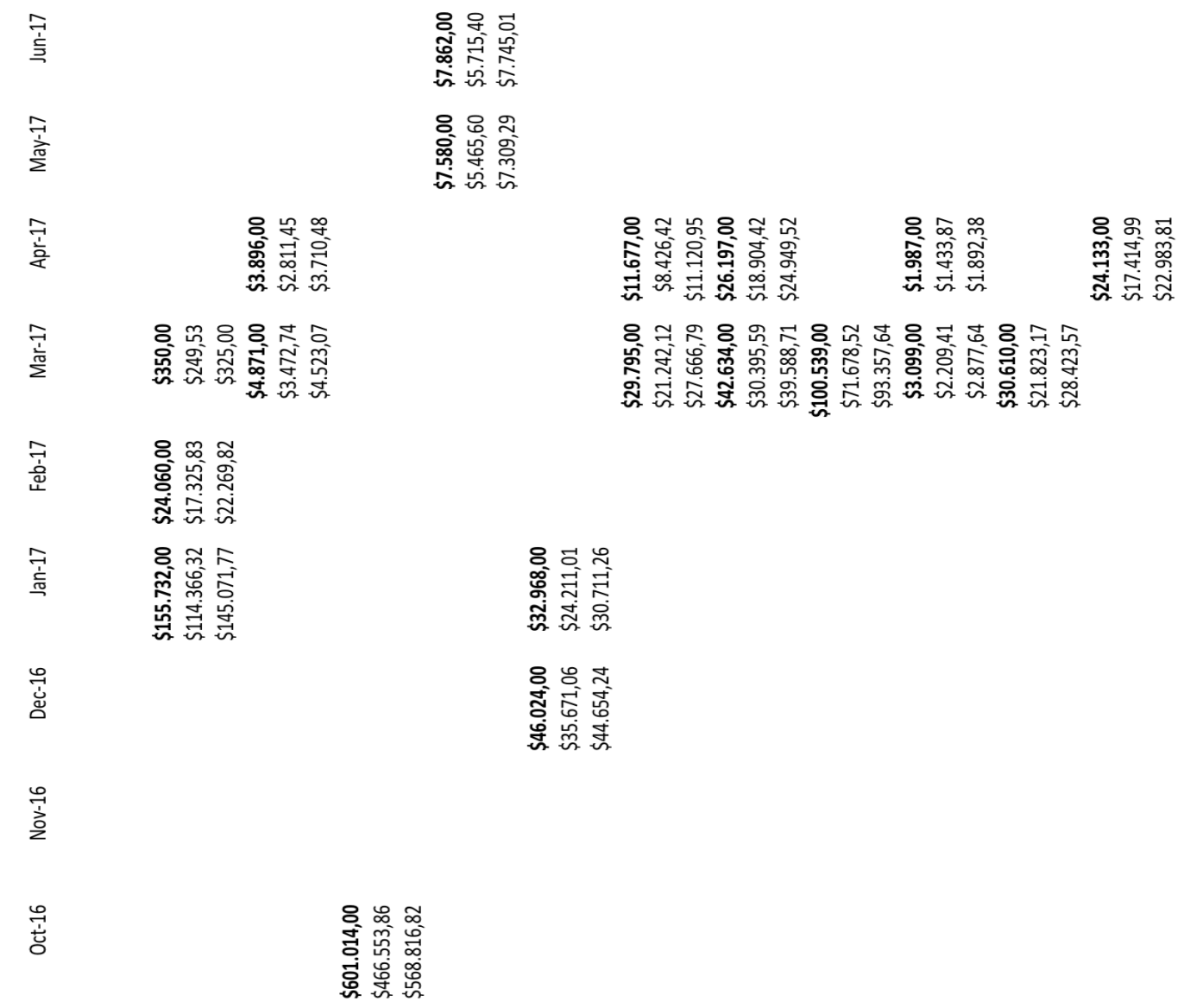

일

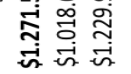

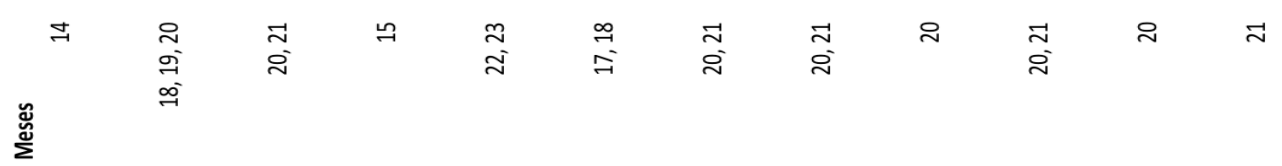

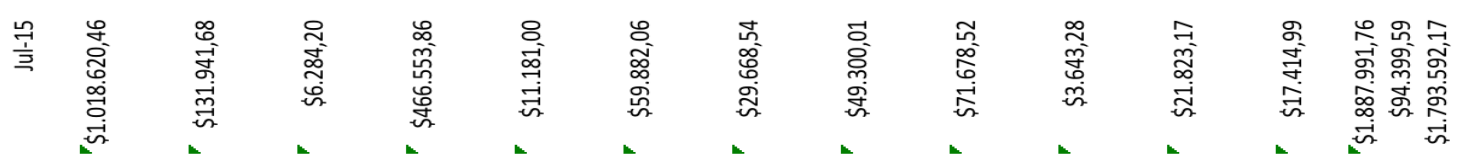

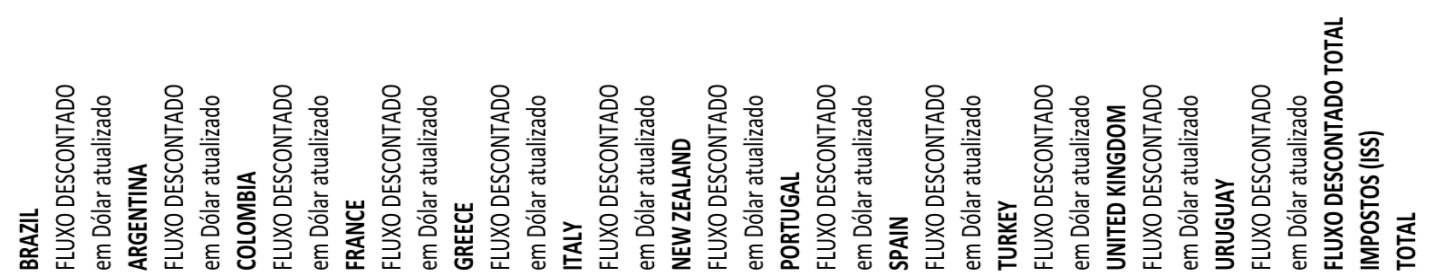




\section{Anexo 2 - Taxa Interna de Retorno: Aquarius}

Filme

\begin{tabular}{|c|c|}
\hline$\$ 1,00$ & Jul-15 \\
\hline$\$ 1.229 .915,10$ & Sep-16 \\
\hline$\$ 568.816,82$ & Oct-16 \\
\hline$\$ 0,00$ & Nov-16 \\
\hline$\$ 44.654,24$ & Dec-16 \\
\hline$\$ 175.783,04$ & Jan-17 \\
\hline$\$ 22.269,82$ & Feb-17 \\
\hline$\$ 196.762,43$ & Mar-17 \\
\hline$\$ 64.657,14$ & Apr-17 \\
\hline$\$ 7.309,29$ & May-17 \\
\hline$\$ 7.745,01$ & Jun-17 \\
\hline \multicolumn{2}{|l|}{$\$ 2.317 .912,88$} \\
\hline 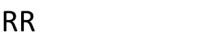 & 179266,477 \\
\hline & 17926647,7 \\
\hline
\end{tabular}

Produtor/Investidor $(37,5 \%)$

$\begin{array}{rrr} & \\ \$ 1,00 & \text { Jul-15 } \\ \$ 461.218,16 & \text { Sep-16 } \\ \$ 213.306,31 & \text { Oct-16 } \\ \$ 0,00 & \text { Nov-16 } \\ \$ 16.745,34 & \text { Dec-16 } \\ \$ 65.918,64 & \text { Jan-17 } \\ \$ 8.351,18 & \text { Feb-17 } \\ \$ 73.785,91 & \text { Mar-17 } \\ \$ 24.246,43 & \text { Apr-17 } \\ \$ 2.740,98 & \text { May-17 } \\ \$ 2.904,38 & \text { Jun-17 } \\ \$ 869.217,33 & \\ \text { RR } & & \\ \% & 78426,12266 \\ & 7842612,27 \%\end{array}$

Para obter tma $\quad 70,07 \%$ 
Anexo 3 - Fluxo descontado de bilheteria: 2 Coelhos

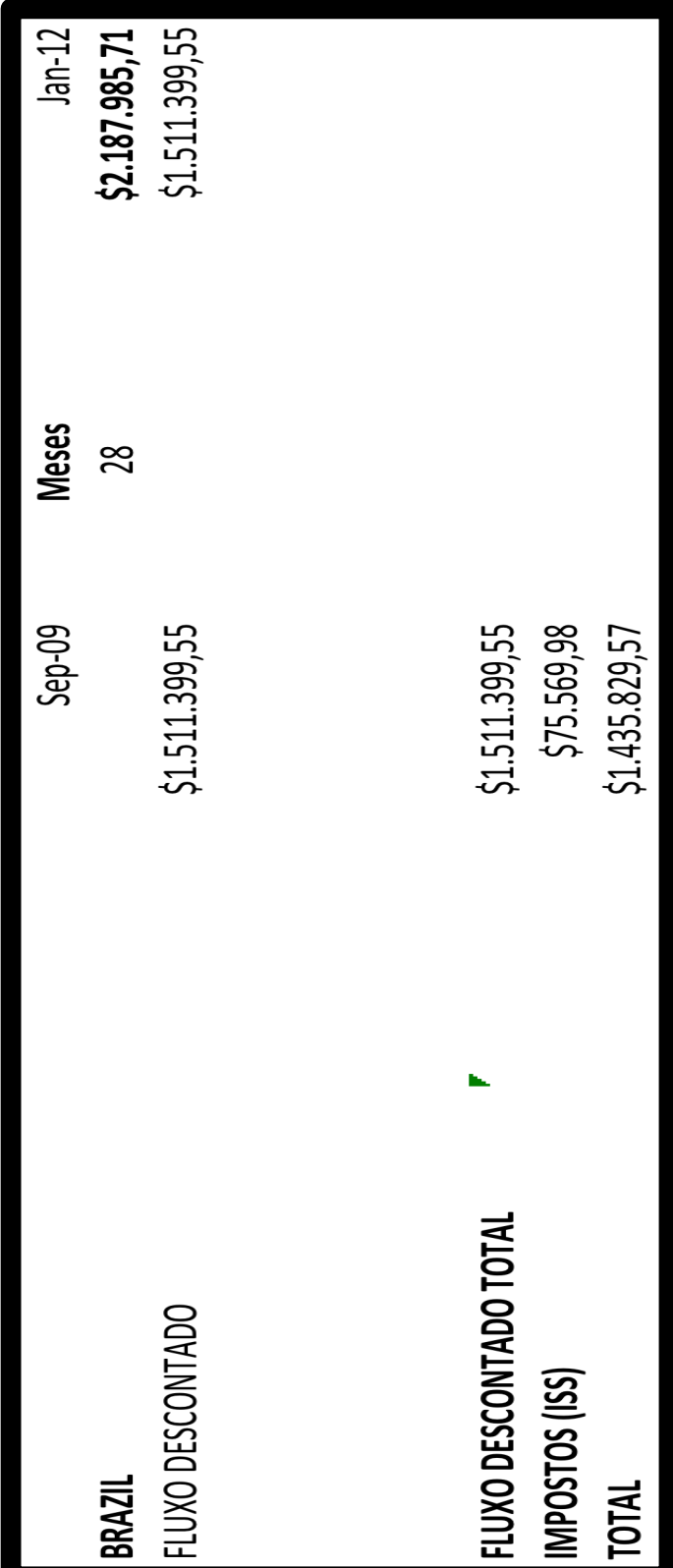




\section{Anexo 4 - Taxa Interna de Retorno: 2 Coelhos}

$\$ 2.187 .985,71$

$\begin{array}{lr}\text { IRR } & 0,1518423 \\ \% & 15,1842302\end{array}$

Para obter TMA, Investidor precisa investir $<\$ 567.000,00$

VPL com Incentivos

VPL sem Incentivos
$-\$ 1.034 .597,62$

$-\$ 1.427 .856,05$
$\$ 820.494,64$

IRR

-0,2433302

$\%$ $-24,333018$ 
Anexo 5 - Fluxo descontado: O Shaolin do Sertão

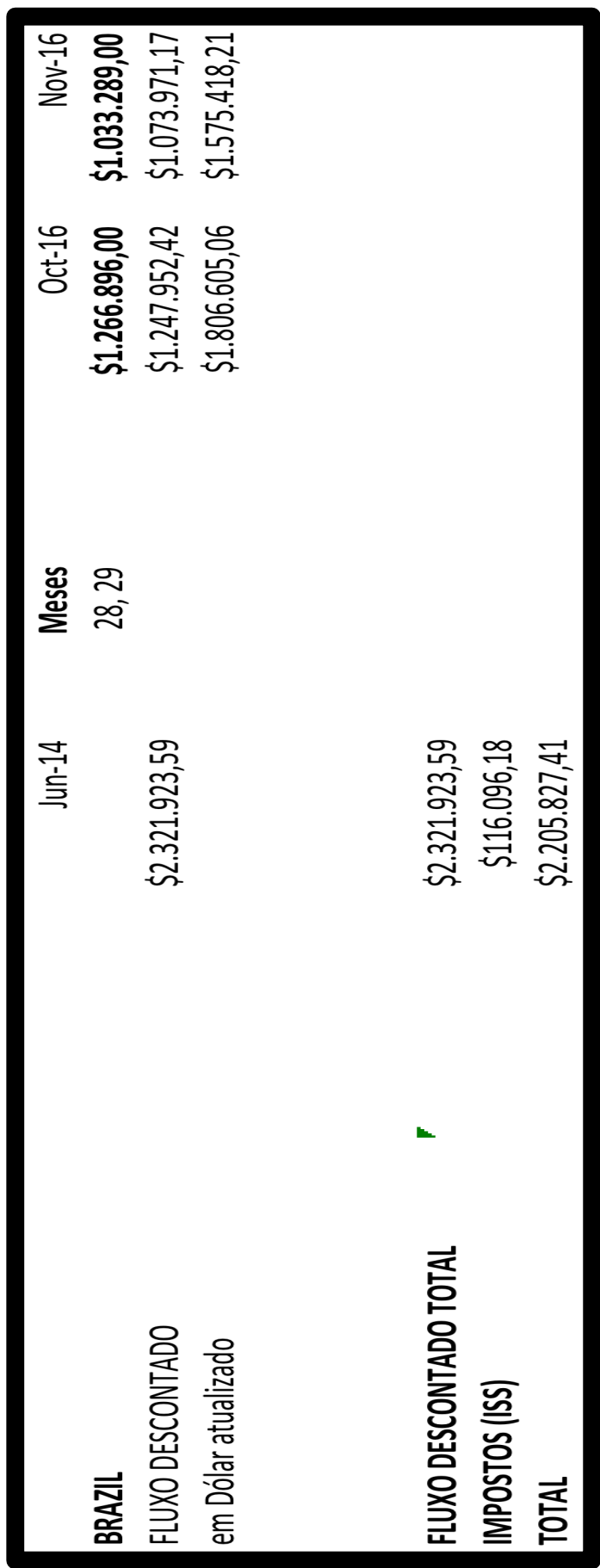




\section{Anexo 6 - Taxa Interna de Retorno: O Shaolin do Sertão}

Filme

$\$ 740.909,09$

$\$ 1.806 .605,06$

$\$ 1.575 .418,21$

Jun-14

Oct-16

Nov-16

Produtor/Investidor (37,5\%)

$\$ 740.909,09$

$\$ 677.476,90$

$\$ 590.781,83$

Jun-14

Oct-16

Nov-16
$\$ 3.382 .023,26$

$\begin{array}{ll}\text { IRR } & 0,89466709 \\ \% & 89,4667089\end{array}$

Para obter TMA, Investidor precisa investir $<\$ 870.000,00$

VPL com Incentivos

VPL sem Incentivos
$\$ 86.276,19$

$-\$ 990.996,54$
$F_{\$ 1.268 .258,72}$

$\begin{array}{ll}\text { IRR } & 0,25382255 \\ \% & 25,3822547\end{array}$

$47,85 \%$ 


\section{Anexo 7 - Pontos Abordados na Entrevista Informal (ANCINE)}

1. Qual é a média orçamentaria de filmes que a ANCINE financia.

R. A média é de, em torno de, $R \$ 7.000 .000,00$

2. O que é "PRODECINE"?

R. PRODECINE, é o braço de captação do fundo setorial.

3. Como funcionam os royalties para Blu-Ray e DVDs, em termo de distribuição de lucros.

R. Royalties variam de $25 \%$ a $50 \%$ para o produtor, enquanto o distribuidor fica com a outra parte dos lucros.

3. A venda de Blu-Rays e DVDs são rentáveis para o produtor?

R. Não muito, principalmente comparado a bilheteria do cinema. Contratos de Blu-Ray e DVDs estão quase em extinção.

4. Porque a distribuidora tem uma fatia tão significante de participação.

R. São responsáveis pelo "P\&A", printing and advertising, que é a divulgação do filme, etapa extremamente importante e custosa, podendo custar até mais do que o orçamento de um filme.

5. Em relação ao PAR e PAQ, o valor dos prêmios precisa ser retornado a ANCINE, após o projeto ter sucesso?

R. Não, estes valores são de fato, prêmios. Tendo o produtor somente a obrigação de destinar estes recursos para projetos.

6. A Agência também faz chamadas públicas para financiar filmes, certo?

R. Sim. Os filmes selecionados recebem financiamento, do fundo da ANCINE.

O fundo tenta recuperar este investimento de volta ao longo de 7 anos. Porém não existe obrigação de retorno caso o projeto não tenha sucesso. 
7. Sugere alguma fonte adicional que eu possa consultar?

R. Sim, a biblioteca da ANCINE pode ser útil. O livro "Film Business: O Negócio do Cinema" também pode ajudar. 


\section{Anexo 8 - Simulação de VPL com CAPM Modificada}

*Esta tabela apresenta uma média ponderada do custo de capital, contemplando a utilização da taxa SELIC de 7\% para capital incentivado, e uma TMA de 17,14\% para capital próprio.

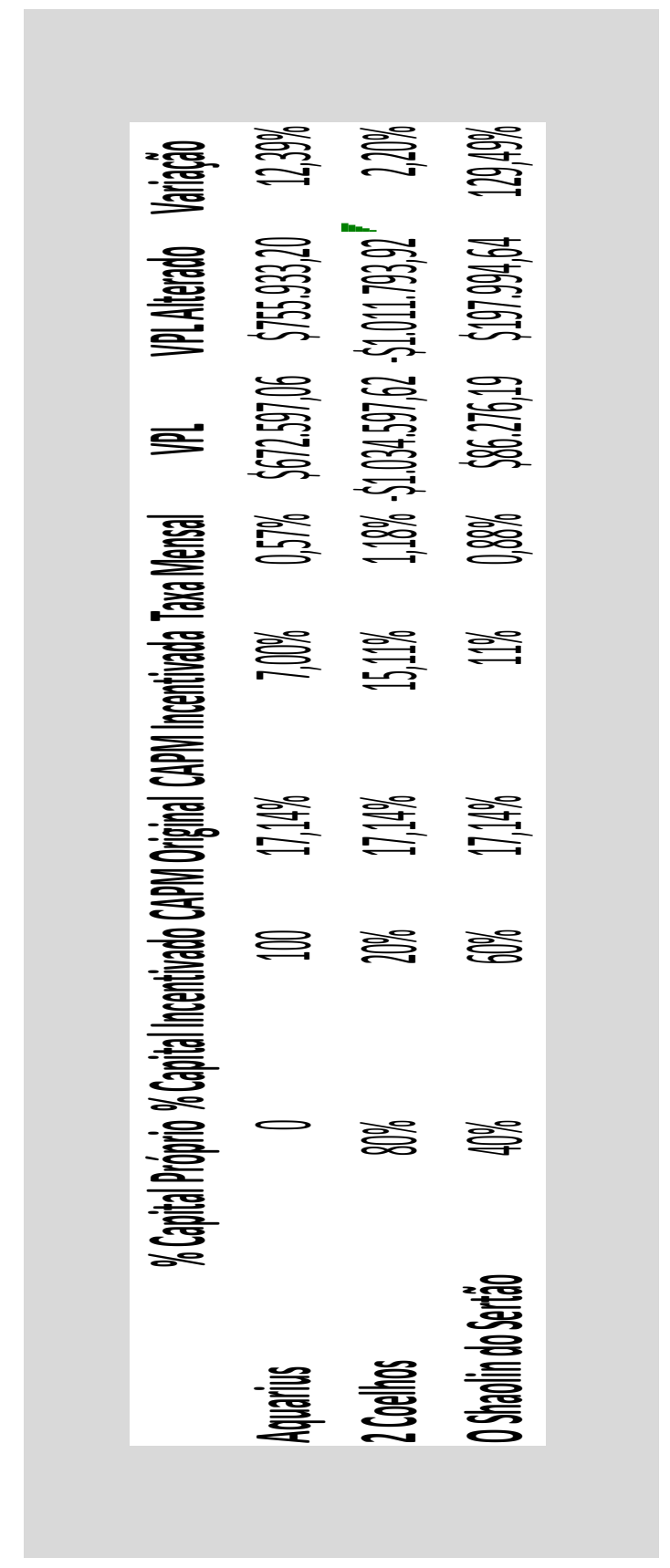

